\title{
A Comparative Analysis of the Nature and Pattern of Employment Among Persons with Severe Mental Disorders
}

\author{
Faseela Jaleel $\cdot$ B. P. Nirmala $\cdot$ Jagadisha Thirthalli
}

Received: 22 October 2014/ Accepted: 5 December 2014/Published online: 20 January 2015

(C) Springer India Pvt. Ltd. 2015

\begin{abstract}
The current study aimed at understanding the nature and pattern of employment among persons with severe mental disorders and compared those who sustained versus lost the job after onset of illness. Data were collected using a semi structured interview schedule from 216 respondents who were diagnosed with severe mental disorders including schizophrenia/schizo affective disorder and psychosis NOS. Out of the 216 respondents, 136 were employed and 80 were not working at the time of study. While comparing employed and unemployed group using Chi square test, females were found to be losing their jobs more $(54.3 \%)$ than male respondents $(33.7 \%)$ after the onset of illness. There was a trend towards unemployment noticed in respondents with higher years of education and more number of respondents was belonging to unskilled worker category (64) out of which $67.2 \%$ were in employed group and $32.8 \%$ in unemployed group. The present study helps in understanding the scenario of employment among persons with severe mental disorders in India and to plan appropriate policies and interventions in addressing employment related issues among the population.
\end{abstract}

Keywords Employment - Severe mental disorders . Schizophrenia $\cdot$ Psychosis

F. Jaleel $(\bowtie) \cdot$ B. P. Nirmala

Department of Psychiatric Social Work, NIMHANS,

Bangalore 560029, India

e-mail: faseela.jaleel@gmail.com

J. Thirthalli

Department of Psychiatry, NIMHANS, Bangalore, India

\section{Introduction}

Recent development in the field of mental health supports the bio-psycho-social model [1] where mental illness is considered to be the result of interaction between a person's biological, psychological and social environment [2]. Therefore, mental disorders pose an impact on one's social and occupational functioning which can also have an impact on the individual's personal and family life. Among all sources of disability, mental health conditions are associated with the highest rates of unemployment: commonly between 70 and $90 \%$ [3]. Employment plays a critical role in the life and recovery of persons with mental illness in terms of clinical improvement, improvement in social functioning and reduction of symptoms [4].

According to 2011 census data, the total number of persons suffering from mental illness in India was 7,22,826 $(2.7 \%$ ), out of which $4,15,732$ were males and 3,07,094 were females [5]. Central Statistics Organization [6] reported that $87.3 \%$ (873 out of 1,000$)$ of persons with mental illness in India were out of labor force. If this data is compared with that of other disabilities, the rate of unemployment among persons with psychiatric disability is lesser compared to mental retardation $(94.3 \%)$ and blindness $(90.7 \%)$, but higher compared to any other types of disability. Shenoy [7] pointed out that even though disabled people in India constitute a significant percentage of the population, their needs for meaningful employment largely remain unmet, in spite of the implementation of the 'The Persons with Disability' Act 1995 . He identified the barriers to enter the labor market as lack of education or low literacy rates, lack of access to training, lack of daily living skills, lack of self esteem and confidence, overprotective parents, rural disconnect from markets, lack of financial resources, preference for government jobs, health 
issues etc. which limits access to labor markets. Other reasons included the nature of the workplace or occupation and employer-perceptions of disabled people.

Mental illness was reported to be associated with higher hazard ratios for employment termination and greater likelihood for unemployment by various studies and reviews [8-10]. While employment offers real benefits to people with experience of mental illness, the reality is that unemployment rates amongst this group are higher compared to the general population. The employment rate among persons with schizophrenia reported in the US ranged from 3 to $42.8 \%$ whereas in UK it was between 4 and $60 \%$ [11]. Most of the studies in western countries report less rates of competitive employment among persons with severe mental disorders especially psychotic disorders. The study by Rosenheck et al. [12] reported that only $14.5 \%$ of the patients were participating in competitive employment whereas Goldberg et al. [13] reported that participants with a psychotic disorder were more likely to be unemployed (55\%) for 5 or more years. Contrary to these, the rates of employment reported in India were comparatively higher than that of developed countries.

Srinivasan and Thara [14] in their follow-up study of people with schizophrenia in India found that the occupational outcome was good in $53 \%$ of patients after 10 years. Apart from that, Srinivasan and Tirupati [15] found that $67 \%$ out of 88 respondents with chronic schizophrenia were employed, among which $93 \%$ were employed in the mainstream. Suresh et al. [16], in a 4 year follow-up study on work functioning of schizophrenia patients in a rural south Indian community reported that $60 \%$ of the 201 respondents assessed during last follow-up were able to hold different occupations, with either no disability or mild-level of disability. However, these findings are not enough to arrive at a conclusion to compare the rate of employment in different countries as there was no standard method for describing or defining employment in these studies. For e.g., in the study by Srinivasan and Thara [14], employed for less than or more than $50 \%$ of the follow up period with no change/improvement in work performance was considered as indicator for good outcome in the study.

Burke-Miller et al. [17] reported that being older (median age of respondents in the study was 38 years) reduces the chances of achieving competitive employment and, age was found to be a significant and non-significant predictor of employment by different studies [18-20]. Marital status was also found to be a significant predictor of employment by few studies $[18,20]$. Previous studies observed no gender differences in obtaining or maintaining competitive employment $[13,17]$ and gender was not a significant predictor of employment $[19,20]$. In terms of education, higher education is reported to be associated with better employment outcomes [17, 19]. Earlier onset and more hospitalizations were significantly associated with unemployment $[9,13]$ and short duration of illness was identified as a predictor of better employment outcomes $[18,21]$. A study in a rural agrarian set up in India [16] had identified adherence to medication as a significant predictor for work functioning and another study reported that history of drug misuse reduces the odds of employment [9].

Even though the employment rates are high in India, the types of jobs undertaken by persons with severe mental disorders are mostly agricultural or unskilled jobs. Srinivasan and Thara [14] in their study mentioned that the good rate of employment could be related to the low education and economic status of respondents and the type of jobs undertaken (trade/service). In the study by Suresh et al. [16], $37.3 \%$ of the respondents were pursuing agricultural work $($ males $=52$; females $=23$ ); $28.9 \%$ were pursuing household jobs (males $=7$; females $=51$ ); $13.9 \%$ were daily wage laborers (males $=15$; females $=13$ ); $3.5 \%$ were skilled laborers; $3.5 \%$ were involved in other jobs, including studentship, private business and professional employment. In another study, $58 \%$ among employed respondents were doing skilled or unskilled manual work whereas $24 \%$ were in professional jobs, $12 \%$ were doing white collar jobs and $7 \%$ were self employed [15].

Nelson and Kim [10] reported that mental illness is associated with greater hazard ratios for employment termination as well as shorter employment spells. Mak et al. [8] in their study on Job Termination among Individuals with Severe Mental Illness Participating in a Supported Employment Program reported that majority of job terminations were unsatisfactory.

Studies in the area of employment among persons with severe mental disorders in India are limited and the available literature does not give prime importance to the effect of mental illness on employment status of respondents. Therefore, the present study aims at understanding the nature and pattern of employment among those diagnosed with severe mental disorders and to compare the statistics between those who continue to work and those who left job after onset of illness.

\section{Methods}

The data presented in this paper is a part of the Ph.D thesis carried out by the researcher. This paper focuses on understanding the nature and pattern of employment among persons diagnosed with severe mental disorders who were employed at some point during or after the onset of illness. The respondents comprised of those who have continued to hold a job (employed) and those who lost their job (unemployed) after the onset of illness. Data were 
collected regarding socio demographic characteristics, illness history and employment profile using a semi structured interview schedule from 216 respondents aged between 18 and 50 years and who were diagnosed with severe mental disorders including schizophrenia/schizo affective disorder and psychosis NOS. The respondents were selected from the Adult Psychiatry Out-Patient unit of the National Institute of Mental Health and Neurosciences (NIMHANS), Bangalore during the period from February 2013 to October 2013. Ethical clearance was received from the NIMHANS ethics committee and written informed consent was obtained from respondents prior to the study. The data were analyzed using ' $R$ ' Statistical Package. Since there were two groups namely employed $(\mathrm{n}=136)$ and unemployed $(\mathrm{n}=80)$, data were analyzed in comparison between the two groups so as present the data in a precise and clear manner.

\section{Results}

\section{Socio Demographic Details}

The results (Table 1 ) showed that $63 \%$ respondents were employed at the time of the study and $37 \%$ lost job or quit the job after onset of illness. The mean age of employed respondents was $35.57 \pm 7.95$ and $36.55 \pm 8.05$ for unemployed respondents. Significant difference was found between groups in terms of sex where $54.3 \%$ of female respondents tend to be unemployed after the onset of

Table 1 Socio demographic details

\begin{tabular}{lllll}
\hline Variable & $\begin{array}{c}\text { Employed } \\
(\mathrm{n}=136)\end{array}$ & $\begin{array}{l}\text { Unemployed } \\
(\mathrm{n}=80)\end{array}$ & $\mathrm{t} / \mathrm{x}^{2}$ & $\mathrm{P}$ \\
\hline Age & $\begin{array}{c}35.57 \\
(7.95)\end{array}$ & $36.55(8.05)$ & 0.87 & 0.39 \\
Sex & $16(45.7)$ & $19(54.3)$ & 5.33 & $\mathbf{0 . 0 2 1}$ \\
Female & $120(66.3)$ & $61(33.7)$ & & \\
$\quad$ Male & & & & \\
Marital status & $89(65.9)$ & $46(34.1)$ & 1.36 & 0.244 \\
$\quad$ Married & $47(58)$ & $34(42)$ & & \\
$\quad$ Unmarried & $9.32(4.53)$ & $10.55(4.68)$ & 1.9 & $\mathbf{0 . 0 5 9}$ \\
Years of education & & & & \\
Education category & & & & \\
$\quad$ Graduate and above & $21(43.8)$ & $27(56.2)$ & 9.91 & $\mathbf{0 . 0 0 7}$ \\
$\quad$ Intermediate/ & $27(71.1)$ & $11(28.9)$ & & \\
$\quad$ diploma & $88(67.7)$ & $42(32.3)$ & & \\
$\quad$ SSLC and below & & & & \\
Domicile & & & & \\
$\quad$ Rural & $65(56.5)$ & $50(43.5)$ & 4.376 & $\mathbf{0 . 0 3 6 *}$ \\
Urban & $71(70.3)$ & $30(29.7)$ & & \\
\hline
\end{tabular}

illness compared to $33.7 \%$ male respondents. When the years of education is high there is a trend which shows that the respondents have more chances of losing jobs $(t=1.9$, $\mathrm{p}=0.059$ ). Majority (120) was found to be educated up to SSLC or below and was mostly employed with only $32.3 \%$ falling to the unemployed category. Results shows that higher the educational qualification, the chances of maintaining job is less (Chi square $=9.91$; $\mathrm{p}=0.007$ ). In terms of the domicile, more number of respondents belonging to urban category was found in employed group with a significant difference from the unemployed group.

\section{Illness History}

In terms of illness history (Table 2), there was no significant difference between both the groups in terms of duration of illness, age of onset, gap taken for initiating treatment, number of admissions, adherence to treatment, and dependence on religious or other indigenous methods of treatment. The mean age of onset of illness was $27 \pm 6.75$ for employed group and $26.6 \pm 6.96$ for the unemployed group. The employed respondents had a mean of $8.57 \pm 5.96$ years of duration of illness whereas unemployed respondents had a mean duration of $9.94 \pm 7.22$ years. Even though there was no significant difference, it was observed that out of the 216 respondents, most of them (153) had never depended on any other treatment and the employed respondents were more in this category i.e., 101 (66\%) compared to the respondents who had depended on other treatment (63) where the employed respondents were only $35(55.6 \%)$. It was also noticed that

Table 2 Employment history-Part A

\begin{tabular}{lllll}
\hline Variable & $\begin{array}{l}\text { Employed } \\
(\mathrm{n}=136)^{* *}\end{array}$ & $\begin{array}{l}\text { Unemployed } \\
(\mathrm{n}=80)^{* *}\end{array}$ & $\mathrm{t} / \mathrm{x}^{2}$ & $\mathrm{P}$ \\
\hline $\begin{array}{l}\text { Total years of } \\
\text { employment }\end{array}$ & $13.34(8.24)$ & $10.91(8.54)$ & 2.07 & 0.04 \\
$\begin{array}{l}\text { Years of job after } \\
\text { onset }\end{array}$ & $6.17(5.21)$ & $4.01(4.49)$ & 3.09 & 0.002 \\
$\begin{array}{l}\text { Change of job after onset } \\
\text { Yes }\end{array}$ & $54(39.7)$ & $31(38.7)$ & 0.019 & 0.89 \\
$\quad$ No & $82(60.3)$ & $49(61.3)$ & & \\
$\begin{array}{l}\text { Break in } \\
\text { employment } \\
\text { (years) }\end{array}$ & $2(3.31)$ & $5.1(4.86)$ & 5.56 & $<0.001$ \\
$\begin{array}{l}\text { Continuity } \\
\text { Intermittent }\end{array}$ & $18(13.2)$ & $24(30)$ & 9.04 & 0.003 \\
$\quad$ Continuous & $118(86.8)$ & $56(70)$ & & \\
Regularity & & & & \\
$\quad \begin{array}{l}\text { Regular } \\
\text { Irregular }\end{array}$ & $107(78.7)$ & $55(68.7)$ & 2.65 & 0.104 \\
\hline
\end{tabular}

** \% within employment status for categorical variables 
out of the employed respondents $(n=136), 72.3 \%$ had never depended on any other treatment whereas in the unemployed category $(n=80)$, it was $65 \%$.

In terms of side effects, significant difference between both the groups was found in those having increased sleep. Respondents experiencing increased sleep were found to be more in unemployed category (13.9 vs $25 \%$ ) with a Chi square value of 4.14 and $\mathrm{p}$ value of 0.042 . It was also noticed that the most occurring side effect is drowsiness (102 out of 216) followed by increased sleep (39 out of 216) and tremors (26 out of 216). Among those experiencing drowsiness, $57.8 \%$ belonged to employed group and $42.2 \%$ belonged to unemployed category whereas $53.8 \%$ of those experiencing tremors were in employed group and $46.2 \%$ were in unemployed group.

\section{Employment History}

Employment history was elicited from both the groups based on employment status and was compared. For employed respondents, details of the job held during interview are presented and for unemployed group, details based on last held job are presented.

When both the groups were compared for employment related variables (Table 2), significant difference was observed in total years of employment, years of job after onset, years of break in employment (duration of break happened in employment due to illness and problems associated with the same) and nature of continuity. No significant difference was found in terms of number of job changes after onset and regularity. Employed group had a significantly higher average in total years of employment $(t=2.07, p=0.04)$ and years of job after onset $(t=3.09$, $\mathrm{p}=0.002$ ), and had a significantly lesser mean rank in years of break in employment. Even though there was no significant difference between groups, it was observed that $85(39.4 \%)$ respondents changed their job after onset of illness. Out of this, $36.5 \%(\mathrm{n}=31)$ did not get back to work or sustain job even if they got back and they remain unemployed whereas $63.5 \%(\mathrm{n}=54)$ were able to get other job and sustain the same.

The regularity in employment was not significantly different between groups (Table 2). Even though there were 21.3 and $31.3 \%$ respondents who were irregular in job respectively in employed and unemployed group, the reasons for irregularity were varied. This was elicited through an additional open ended question which was then categorized into various reasons for irregularity. Out of the 29 employed respondents who were irregular in their job, $13(44.8 \%)$ reported illness, $6(20.7 \%)$ mentioned drowsiness as the reason for irregularity and remaining 10 $(34.5 \%)$ were irregular due to the seasonal nature of job where job is not available every day. Among the 25
Table 3 Employment history-Part B

\begin{tabular}{lllll}
\hline $\begin{array}{l}\text { Employment } \\
\text { category }\end{array}$ & $\begin{array}{l}\text { Employed } \\
(\mathrm{n}=136)^{* * *}\end{array}$ & $\begin{array}{l}\text { Unemployed } \\
(\mathrm{n}=80)^{* *}\end{array}$ & $\mathrm{t} / \mathrm{x}^{2}$ & $\mathrm{P}$ \\
\hline $\begin{array}{l}\text { Unskilled worker/ } \\
\text { Semi skilled }\end{array}$ & $87(64)$ & $51(63.8)$ & 1.681 & 0.432 \\
$\begin{array}{l}\text { worker/Clerical/ } \\
\text { Shop owner/ }\end{array}$ & & & & \\
$\quad$ Farmer & & & & \\
Skilled worker & $31(22.8)$ & $14(17.5)$ & & \\
Semi professional/ & $18(13.2)$ & $15(18.8)$ & & \\
$\quad$ Professional & & & & \\
Income category & & & & \\
$\quad \leq 1,600$ & $19(14)$ & $24(30)$ & 16.39 & 0.001 \\
$1,601-4,809$ & $49(36)$ & $34(42.5)$ & & \\
$4,810-8,009$ & $36(26.5)$ & $17(21.3)$ & & \\
$\geq 8,010$ & $32(23.5)$ & $5(6.2)$ & & \\
Family support & & & & \\
Poor & $32(23.5)$ & $52(65)$ & 36.45 & $<0.001$ \\
Good & $104(76.5)$ & $28(35)$ & & \\
Disclosure to employer* & & & \\
Yes & $75(72.8)$ & $35(55.6)$ & 5.209 & 0.022 \\
No & $28(27.2)$ & $28(44.4)$ & & \\
\hline
\end{tabular}

* Total number of respondents differ for disclosure

** \% within employment status for categorical variables

unemployed respondents who reported to be irregular when they were working, majority $(\mathrm{n}=22$ i.e., $88 \%)$ reported illness as reason for irregularity whereas $2(8 \%)$ reported drowsiness and 1 (4\%) mentioned seasonal nature of job.

There was no significant difference between both groups in terms of the employment they held (Table 3). More number of respondents was belonging to unskilled worker/ semiskilled worker/clerical/shop owner/farmer category $(138 / 216)$ out of which $63 \%$ were in employed group and $37 \%$ in unemployed group. Most of the respondents were receiving/received either an income up to 1,600 or between 1,601 and 4,809 and the percentage of respondents in these categories was more in unemployed group. Employed respondents reported of receiving better support from family in continuing employment whereas family support for accessing a job was found to be poor among unemployed group. There was significant difference between groups in terms of disclosure where non disclosure was high among unemployed respondents.

\section{Discussion}

The discussion focuses on the trend of employment among persons with severe mental disorders based on the study results. Unlike previous studies which compared 'employed' versus 'unemployed', the present study compared those who sustained their jobs (employed) and those 
who lost job (unemployed) after the onset of illness. Thus, the representation of 'employed' and 'unemployed' differs in the present study and hence, a direct comparison with other studies is difficult. However, the researcher tries to understand the results in the context of available literature. The study had looked into the perspective of employment from the point of view of persons with severe mental disorders. The perceptions of other stakeholders like employers, family members, colleagues and the society who are equally involved in employment of these respondents were not part of the study. Hence, the results represent the opinion of persons diagnosed with severe mental disorders and a conclusion can be arrived only when the situation is studied from the point of view of other stakeholders too.

In the current study, there were $63 \%$ employed respondents who were working and $37 \%$ unemployed respondents who lost their job or quit the job during the course of their illness. The finding is similar to the results of available Indian studies [14-16]. As discussed by previous Indian studies, the reasons for the observation of higher rate of employment may be that most people have lesser education, belong to lower economic status or rural agrarian economy and due to the types of jobs undertaken. The study could not find any difference between employed and unemployed group in terms of age which supports the findings by Nordt et al. [19] in which age was not a predictor of employment status. Previous studies found that having a history of current or past marriage is a predictor for competitive employment $[18,20]$. The present study found that marital status and employment status are not associated.

There was significant difference within and between both groups in terms of sex where female respondents were found to be more in unemployed category than male respondents. The present finding is different from the previous studies $[13,17,19,20]$. Again, this finding could also be related to the cultural situation persisting in India where men are usually considered to be the breadwinners of the family. This could contribute to the comparatively lesser number of women (Table 1) in the study. In such situation, when the women start suffering from a severe mental health condition, they choose to quit job if there is another earning member in the family. By design, the study excluded never employed people, homemakers and students and therefore, the results only reflect the employment status of people who are earning.

In terms of domicile, the study found that belonging to rural area reduces the possibility of maintaining employment. More respondents from urban domicile were in employed group which may be due to the number of opportunities available in urban setting. Those from rural area were either employed in unskilled labor or semiskilled work like weaving, tailoring or working in garment factories. Once they lose a job, the avenues in rural settings are less that they may not find other similar opportunities and therefore, remain unemployed. However, these findings could not be supplemented with previous Indian studies because those studies had participants primarily from rural agrarian economies [14-16].

The study demonstrated a trend in which more number of unemployed respondents was having higher years of education. The finding is contradictory to foreign studies where higher education was associated with better employment outcomes [17, 19]. The finding supports the observation in a previous Indian study [14] which mentioned, 'the good rate of employment could be related to the low education of respondents'. The current study found that majority of the respondents had lesser education among which, most of them could sustain their employment and the reason could be that the complexity involved in jobs available for less educated people may be less challenging. Since the universe of the study was a government hospital which provides tertiary care services, there is a more likelihood that below poverty line (BPL) beneficiaries will be availing the services and therefore, lesser educational qualification may be attributed to the economic status of the respondents. The difficulty in sustaining employment for those with higher education may be due to nature and profile of job where the tasks are generally time bound in which they are given deadlines for most of the assignments.

Side effects like increased sleep, drowsiness and tremors were observed to be higher among unemployed respondents. These are threats to productivity and maintenance of job for an individual with severe mental disorder if not to gain an employment. Increased sleep can be a reason for stigma at workplace and other practical difficulties like not reaching office on time. It is visible that increased sleep leads to unemployment as most people with this difficulty belonged to unemployed category. The clinicians should therefore try and see if the medications can be adjusted so that there is a proper balance between symptoms and functioning of the individual. This also implies the need for regular review of occupational functioning of the patients and providing appropriate interventions immediately so that they can maintain their jobs with less disability. The mental health professionals should watch for less symptomatic benefit of medication. Otherwise, adverse effects of medication may create a negative canvas for psychiatric treatment and people may develop negative attitude towards treatment.

Employed group had a significantly higher average in total years of employment and years of job after onset, and had a significantly lesser mean years of break in employment which suggests that the years of employment lost for 
those in unemployed category is high. This is similar to the finding of the Indian study in which duration of employment was high for those who were considered to have better occupational outcome [14]. It could be assumed from these findings that even if the unemployed respondents wanted to get back to work, the higher years of break in their job would have challenged them from accessing new jobs. In some cases, the illness may be too severe that it takes longer time to resolve. Along with that, in the course of illness, people with severe mental disorders tend to lose self-confidence regarding their abilities and this makes them to avoid getting back to work. It could also be the negative symptoms that would have reduced their intrinsic motivation to work.

Even though there was no significant difference between groups, it was observed that 85 respondents out of 216 changed their job at least once after the onset of illness. The reasons for changing jobs were not studied. So it is not clear whether the respondents who quit one job and joined new ones changed the job due to better opportunities. The frequent job changes among normal population do not always lead to unemployment because they tend to grab better opportunities before quitting the job. But in case of persons with severe mental disorders, the study found that $36.5 \%$ of those who changed job remained unemployed. Thus, it could be assumed that they had left the job even without getting a better opportunity which is not same in the case of normal population.

The above observations on employment history reveal that any absence or any length of absence from work is a proxy indicator for employment. It indicates the need for taking any loss of employment as a priority and the need to reemploy them as soon as possible. The psychiatric social work professionals should be involved to address this need by making use of available resources and by networking with the various companies and employers for job placement. Implementation of supported employment, more specifically individual placement and support (IPS) model by Becker and Drake would benefit this population as the primary aim of this model is to immediately place the candidate in a job according to the candidate's preference $[22,23]$.

When the groups were compared based on the last job held by the unemployed and the present job of employed respondents, there was no significant difference in terms of category of employment held. There were 48 respondents who were educated up to graduation and above who had the possibility of getting jobs in semi-professional/professional category. But incidentally, there were only 33 respondents in semi-professional/professional category. This finding once again strengthens the assumption that people with higher education have higher risk of losing their jobs. It also calls for the need to study this further and understand whether they are ready to settle for jobs which are lower (which do not match their qualification), develop a work habit and then grow up the ladder. The study also found significant difference between both the groups when the income earned per month was compared.

The study found that a significantly higher number of employed respondents had disclosed their illness in workplace compared to unemployed group, which shows that disclosing illness does not always lead to unemployment. Similar findings were reported by Koletsi et al. [24] in which most of those who disclosed their illness received positive response and felt no discrimination. The present result shows that disclosure of illness had not affected the employment of respondents in many instances. However, the results cannot be generalized considering the social stigma prevailing in the society and therefore disclosure can lead to either positive or negative effect on the employment of the person.

\section{Conclusion}

The present study gives an idea about the current scenario of employment among persons with severe mental disorders in India. Family support came out as an important external factor for maintaining employment and that needs to be enhanced for improving employability of persons with severe mental disorders. At the same time, workplaces/employers need to be sensitized to make them understand the capability of persons with severe mental disorders as productive individuals and thereby promote mental health friendly workplaces. Attempts should also be made to understand the perspective of employers and other stakeholders on employment of persons with severe mental disorders and initiatives should be made to address their concerns. The higher rate of loss of job among respondents with higher educational qualification also calls for the need for adequate interventions from mental health professionals.

\section{References}

1. Engel GL. The need for a new medical model: a challenge for biomedicine. Science. 1977;196:129-36.

2. Waddell G, Aylward M. Models of sickness. London: Royal Society of Medicine Press Ltd; 2010.

3. Funk M, Drew N, Freeman M, Faydi E. Mental health and development: targeting people with mental health conditions as a vulnerable group. Geneva: World Health Organization; 2010.

4. Salzer MS, Baron RC, Brusilovskiy E, Lawer LJ, Mandell DS. Access and outcomes for persons with psychotic and affective disorders receiving vocational rehabilitation services. Psychiatr Serv. 2011;62(7):796-9. http://www.ncbi.nlmnih.gov/pubmed/ 21724795 . 
5. Census of India. Census of India 2011-Data on disability. New Delhi: office of the registrar general and census commissioner. 2014; http://www.censusindia.gov.in/2011census.

6. Chakrabarti S. Disability statistics in measuring some gender dimensions: case India. Central Statistics Organization: Government of India; 2010.

7. Shenoy M. Persons with disability and the India labour market: challenges and opportunities. Geneva: International Labour Organization; 2011. p. 46.

8. Mak DCS, Tsang HWH, Cheung LCC. Job termination among individuals with severe mental illness participating in a supported employment program. Psychiatry. 2006;69(3):239-48. http:// www.ncbi.nlm.nih.gov/pubmed/17040175.

9. Marwaha S, Johnson S, Bebbington P, Stafford M, Angermeyer $\mathrm{MC}$, Brugha T, et al. Rates and correlates of employment in people with schizophrenia in the UK, France and Germany. Br J Psychiatry. 2007;191:30-7. http://www.ncbinlm.nih.gov/ pubmed/17602122.

10. Nelson R, Kim J. Survival of the fittest: impact of mental illness on employment duration. 2008;0-55. http://home.utah.edu/ $\sim$ u0154844/EmploymentDurationRN-081020.pdf.

11. Marwaha S, Johnson S. Schizophrenia and employment: a review. Soc Psychiatry Psychiatr Epidemiol. 2004;39(5):337-49. http://www.ncbi.nlm.nih.gov/pubmed/15133589.

12. Rosenheck R, Leslie D, Keefe R, McEvoy J, Swartz M, Perkins $\mathrm{D}$, et al. Barriers to employment for people with schizophrenia. Am J Psychiatry. 2006;163(3):411-7. http://www.ncbi.nlm.nih. gov/pubmed/16513861.

13. Goldberg RW, Lucksted A, McNary S, Gold JM, Dixon L, Lehman A. Correlates of long-term unemployment among innercity adults with serious and persistent mental illness. Psychiatr Serv. 2001;52(1):101-3. http://www.ncbi.nlm.nih.gov/ pubmed/ 11141538.

14. Srinivasan TN, Thara R. How do men with schizophrenia fare at work? A follow-up study from India. Schizophr Res. 1997;25(2):149-54. http://www.ncbi.nlm.nih.gov/pubmed/ 9187014.

15. Srinivasan L, Tirupati S. Relationship between cognition and work functioning among patients with schizophrenia in an urban area of India. Psychiatr Serv. 2005;56(11):3-8.
16. Suresh KK, Kumar CN, Thirthalli J, Bijjal S, Venkatesh BK, Arunachala $\mathrm{U}$, et al. Work functioning of schizophrenia patients in a rural south Indian community: status at 4-year follow-up. Soc Psychiatry Psychiatr Epidemiol. 2012;47(11):1865-71. http:// www.ncbi.nlm.nih.gov/pubmed/22419163.

17. Burke-Miller JK, Cook JA, Grey DD, Razzano LA, Blyler CR, Leff HS, et al. Demographic characteristics and employment among people with severe mental illness in a multisite study. Community Ment Health J. 2006;42(2):143-59. http://www.ncbi. nlm.nih.gov/pubmed/16404685.

18. Honkonenn T, Stengard E, Virtanen M, Salokangas RKR. Employment predictors for discharged schizophrenia patients. Soc Psychiatry Psychiatr Epidemiol. 2007;42:372-80.

19. Nordt C, Müller B, Rössler W, Lauber C. Predictors and course of vocational status, income QOL etc. Soc Sci Med. 2007;65(7): $1420-9$.

20. Tsang HWH, Fung KMT, Leung AY, Li SMY, Cheung WM. Three year follow-up study of an integrated supported employment for individuals with severe mental illness. Aust N Z J Psychiatry. 2010;44(1):49-58. http://www.ncbi.nlm.nih.gov/ pubmed/20073567.

21. Michon HWC, van Weeghel J, Kroon H, Schene AH. Personrelated predictors of employment outcomes after participation in psychiatric vocational rehabilitation programmes-a systematic review. Soc Psychiatry Psychiatr Epidemiol. 2005;40(5):408-16. http://www.ncbi.nlm.nih.gov/pubmed/15902412.

22. Becker DR, Drake RE. A working life for people with severe mental illness [internet]. Oxford: Oxford University Press; 2003. http://www.oxfordscholarship.com/view/10.1093/acprof:oso/ 9780195131215.001.0001/acprof-9780195131215.

23. Bond GR. Supported employment: evidence for an evidencebased practice. Psychiatr Rehabil J. 2004;27(4):345-59. http:// www.ncbi.nlm.nih.gov/pubmed/15222147.

24. Koletsi M, Niersman A, van Busschbach JT, Catty J, Becker T, Burns T, et al. Working with mental health problems: clients' experiences of IPS, vocational rehabilitation and employment. Soc Psychiatry Psychiatr Epidemiol. 2009;44(11):961-70. http:// www.ncbi.nlm.nih.gov/pubmed/19280083. 